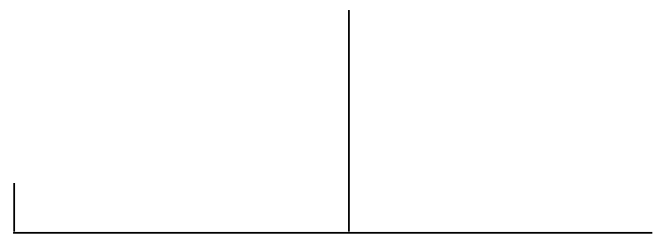

Rev. Latinoam. Psicopat. Fund., São Paulo, v. 13, n. 2, p. 356-360, junho 2010

As diversas faces do cuidar: Novos ensaios de psicanálise contemporânea Luís Cláudio Figueiredo São Paulo: Escuta, 2009. 232p

\title{
Cuidar na clínica e na cultura
}

O subtítulo do novo livro de Luís Cláudio Figueiredo sugere que este é uma espécie de continuação do precedente, Psicanálise. Elementos para a clínica contemporânea (Escuta, 2005), contendo textos que "foram sendo escritos entre amigos e para amigos". Não surpreende, portanto, que o cuidar esteja implícito a essa origem em "grupos e redes de trabalho que dão sentido e sustentação ao que faço" (p. 11). Não obstante, encontramos nessa coletânea a marca habitual dos escritos do autor, do cuidado extremo para com o leitor: além da conhecida clareza de sua escrita, ele cuida em situar cada texto no conjunto da coletânea e em relação aos outros. Ainda em relação aos títulos dos livros, cabe perguntar sobre a insistência em frisar o "contemporâneo". O exercício da psicanálise na atualidade requer o cumprimento de duas exigências entrelaçadas: a primeira toca a relação do psicanalista, em seu trabalho e discurso, com sua comunidade e tradição onde se faz necessário o "atravessamento dos paradigmas"; a segunda impõe ao analista le- 
var em conta sua inserção, assim como de sua clientela, na cultura atual, com suas características específicas. São demandas éticas da psicanálise. Os textos do livro ilustram em ato essa constatação, demonstrando que nenhuma obra ou escola pós-freudiana pode sustentar isoladamente a missão de "cuidar" se o analista que a utiliza, sendo inserido em certa corrente, não puder transitar entre os núcleos conceituais em torno dos quais essas escolas se aglutinaram até os anos 1950-1960 do século passado. Como exemplo desse atravessamento dos paradigmas assiste-se hoje ao surgimento de estilos e pensamentos clínicos que fazem justiça tanto à pulsão como às relações de objeto; que levam em conta, de um lado, o desejo e, de outro, o desamparo e a dependência original; que pensam em termos de conflito e de déficits, de falhas; que investigam a fantasia e o trauma; e que dão atenção ao intrapsíquico e ao intersubjetivo. $\mathrm{O}$ outro aspecto da atual civilização, onde, entre outros, a exasperação pela segurança e a carência por uma confiabilidade, refletindo desconforto e alienação crescentes, aumentam gradualmente, com os avanços tecnológicos que aparentemente são promovidos por políticas de promessas de bem-estar privado e social; esses colocam cada vez mais em xeque o alicerce da constituição subjetiva e de seus fundamentos primitivos, como demonstra o largo espectro das configurações clínicas que chegam hoje aos nossos consultórios, desde as patologias narcísicas e os casos-limite, e suas variantes de caráter e de conduta coercitiva (drogadição, compulsões de risco e outras antissociais), e passando pelas perversidades licenciadas até as regressões somáticas.

A psicanálise é, portanto, convocada, mais do que nunca, a prover e a provar a eficácia de seu ofício em cuidar. $\mathrm{O}$ autor foca neste livro, ao atravessar os paradigmas, as características que a habilitam para tanto. $\mathrm{O}$ cuidado no trabalho psicanalítico integra o exercício da metapsicologia, onde se encontra, também, a inteligibilidade das psicopatologias. O ponto de partida do ser humano é, nas palavras do autor, uma loucura precoce, e a constituição da vida psíquica é sempre obra de um cuidado despendido pelo outro que consiste em tentar implantar $o$ sentido, uma rede de sentidos, uma subjetividade. A subjetividade implica, portanto, a construção pela intersubjetividade ou, em outras palavras, a instauração de um intrapsíquico de origem, de ordem e de funções intersubjetivas. O objeto originário veicula concomitantemente as seguintes dimensões intersubjetivas: 1. Inter-subjetividade trans-subjetiva, instaurada pelo que Winnicott denomina de identificação primária do adulto com o bebê, uma espécie de terraplanagem (para um vir a ser e a dar sentidos), que, ao se imbricar na demanda do bebê pela fusão (em função de sua exasperação em anular a noção da falta e da separação) dota o último de estrutura enquadrante (Green), palco subjetivo que, posteriormente, o servirá de meio de endereçamento aos objetos; 2. Intersubjetividade 
traumática que seduz, incita, interpela e reclama, puxando o bebê "para fora" em direção ao mundo; 3. Intersubjetividade interpessoal que reflete, reconhece e testemunha o bebê e seus atos; 4. Intersubjetividade intrapsíquica que compreende as relações acima criadas como universo subjetivo a partir deste trabalho do objeto, do seu cuidado. A constituição psíquica significa a instauração dessas funções intersubjetivas, ou seja, a capacitação do sujeito, enquanto tal, para a intersubjetividade. Uma obra e tarefas que se prolongam, sofisticando-se, durante toda a vida.

São essas as exigências gerais da subjetividade. Falta explicitarmos o substrato inicial que as condiciona, assim como o processo e a técnica de sua instalação: o que disponibiliza o bebê, em seu estado inicial, para o cuidado e o projeto intersubjetivo do adulto, situa-se no que Melanie Klein formulou de fantasia inconsciente (nossa interpretação). As fantasias inconscientes são representantes do que no soma e na psique está em busca de expressão, realização, predominantemente imaginativa; eu diria, do que almeja se figurar e se presentificar (respectivas traduções, de Botella e Laplanche para a darstellbarkeit freudiana), ou seja, do que é, no bebê, exasperação em vir a ser. Nessa disposição para a subjetivação, a fantasia inconsciente enquanto "poder imaginativo do corpo na 'direção de' e 'em resposta' a ambientes e seus objetos" (p. 26) segue roteiros e esquemas que situam o pré-sujeito em um plano de idealidade, ou seja, à distância, excluído e, portanto, disposto a invadir - identificando-se projetivamente - o terreno dos bens do objeto (o ventre materno em posse do pênis do pai, dos bebês e do casal combinado). As relações objetais iniciais se inauguram, portanto, já tingidos pelo universo do desamparo sob o regime primitivo da idealidade superegoica, com sua extrema violência. O ganho, aqui, na descrição da fantasia inconsciente oferecida pelo autor é apontar como ela abriga uma abertura, uma receptividade à empreitada cultural do objeto, do cuidado em meio ao qual se forma, como ego, o terreno intersubjetivo com suas quatro dimensões. Este processo, em que se configura a depressividade (Fédida unindo Klein e Winnicott), indo na contramão da idealidade primordial, é conduzido pela técnica subjetiva identificadora, contratransferencial, de implicação e reserva, conceitos elaborados há anos pelo autor e que voltam a crescer neste livro. O segundo e o último capítulo do livro (A clínica segundo Klein e O campo superegoico na teoria e clínica) lidam com este enredo.

Nossa descrição privilegiou o viés constitutivo que, certamente, não compreende o plano em que se desenrola, no livro, o tema do cuidado e o substrato sobre o qual incide. O autor foca os eixos da clínica e dos fenômenos culturais. Seguindo nossa própria opção em iluminar, no livro, certa perspectiva do cuidado, sua ação e seu objeto, destacamos, em seguida, outros dois capítulos extre- 
mamente significativos. O primeiro lida com a questão da confiança e sua relação com os investimentos e apostas libidinais e os perigos que acarretam. A questão é tratada atravessando as elaborações de Balint, Winnicott e Green e que nos parecem reeditar o que em Freud foi balizado no entrelaçamento entre correntes afetivas (oriundas do amor primário da ternura infantil) e as sensuais, as últimas apoiadas sobre as primeiras. Embora o autor lide com o tema em relação à clínica e à cultura contemporâneas, Freud também previa semelhante desafio para a manutenção deste enlace que tende a se desgastar com os avanços da civilização (ver o texto de 1912 sobre a degradação da vida amorosa). Sendo as correntes afetivas precursores dos sentimentos sociais (Freud, 1905), a confiança que lhes é implícita se vincula com a substância intersubjetiva, sobretudo a trans-subjetiva, tributária do trabalho do objeto. Em Green, ela é veiculada pela estrutura enquadrante como precipitado das identificações, o negativo, do objeto primário que constitui o pano de fundo do sujeito, capacitando-o a sustentar as correntes sensuais, se arriscando a investir as situações e objetos contingentes do mundo.

Obra do cuidado, a confiança nos transporta para um caráter mais geral desses objetos criados pela e na intersubjetividade. A ênfase dada acima para a essência cultural e social da matéria psíquica criada junto ao objeto se desloca para outro aspecto, a sua lógica paradoxal. Talvez tudo que diga respeito ao inconsciente, a apreensão do mesmo, fenomenal e existencialmente, nos defronta justamente com sua estrutura paradoxal. Foi Winnicott quem precisou não só a experiência cultural como universo intermediário e transicional, mas também esta sua lógica paradoxal. No terceiro capítulo, Figueiredo apresenta três teses sobre o paradoxo. A primeira, como matriz da condição humana e da experiência originária do bebê: a solidão essencial que é, ao mesmo tempo, comunhão absoluta com o meio. A segunda, como figurando na lógica e no estilo das teorias psicanalíticas. A terceira, como dispositivo clínico, operante, da psicanálise.

Não vou me deter sobre outros capítulos do livro (V, VI e VII), focados na técnica do cuidado e no processo analítico, mas vou mencionar dois capítulos em que as carências do cuidado por parte dos objetos primários são elaboradas em relação, de um lado, à saída atual do adolescente para a vida adulta e, de outro, à tragédia da vida urbana brasileira. Esses capítulos focalizam dois filmes: o primeiro A vida sonhada dos anjos (Erick Zonca, 1998) e o segundo Cidade de Deus (Kátia Lund e F. Meireles). O campo social ilumina, no primeiro caso, a psicopatologia esquizoide e antissocial e, no segundo, a regressão narcísica ao regime em que rege o claustro do intestino grosso da geografia mental anal, conforme as elaborações de Meltzer. Notável é a capacidade do autor em tecer problemáticas sociais às do sofrimento e desvios psíquicos sem reduzir as primeiras ao campo da metapsicologia, nem as segundas a uma etiologia sociológica. 


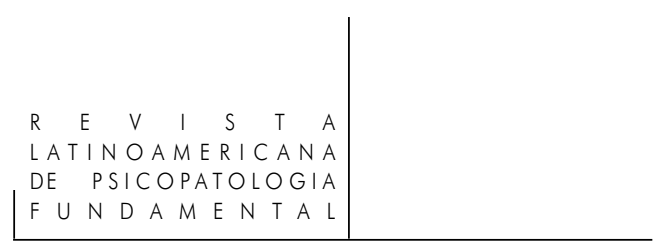

Por fim, cabe perguntar se as descrições fenomenológicas das matrizes da intersubjetividade como matéria do cuidado provido nos estágios constitutivos do bebê e que prosseguem nos cuidados da vida adulta, em que se conta a clínica psicanalítica entre outras instituições e espaços de convívio social, são suficientes, mesmo quando substanciados pelos aportes kleinianos, bionianos e winnicottianos são suficientes. Nossas alusões a Freud pretendem lembrar que essas descrições fenomenológicas devem suas manifestações à estrutura histórica basal do humano revelada por Freud, a do Édipo e da castração, instaurada pelo assassinato do pai primevo. A constatação de Freud de que a mãe é mensageira da castração - ou seja, a ela cabe despachar o bebê para o mundo, provendo-o de subsídios para a aquisição de sentimentos sociais, as coordenadas intersubjetivas do intrapsíquico - comporta toda a metapsicologia do cuidado que o autor nos oferece nessas belas e sábias páginas. Mais um livro que vale muito visitar.

\section{Daniel Delouya}

Psicanalista; Membro efetivo da Sociedade Brasileira de Psicanálise de São Paulo - SBPSP (São Paulo, SP, Brasil); e do Departamento de Psicanálise do Instituto Sedes Sapientiae (São Paulo, SP, Brasil); autor, entre outros, de Depressão, estação psique (Escuta, 2002) e Torções na razão freudiana (Unimarco, 2005).

Rua Capote Valente, 439/104

05409-001 São Paulo, SP, Brasil

Fone: (11) 3063-0018

e-mail: danieldelouya@gmail.com 